\title{
Social Comparisons and Cooperation during COVID-19*
}

\author{
Shuhei Kitamura ${ }^{\dagger} \quad$ Katsunori Yamada $^{\ddagger}$
}

November 2, 2021

\begin{abstract}
We conduct a randomized survey experiment during the pandemic to examine the effects of information treatments on individuals' cooperation with social distancing measures. Using a $2 \times 2$ factorial design, we examine the effects of social comparisons and a powerful messenger. Based on a sample of about 3,000 respondents, we find that our subjects cooperated with social distancing measures more when they understood they had spent a relatively long time outside the home compared with the social norms in the previous week. By contrast, we find no evidence that a powerful messenger increases the effectiveness of the message.

Keywords: social comparisons, power of messenger, information treatment, randomized controlled trial

JEL code: D91, C93, I12, I18
\end{abstract}

${ }^{*}$ Kitamura acknowledges the financial support from JSPS (18K12768). Yamada acknowledges the financial support from JSPS (20H01479). The authors contributed equally to the study. We would like to thank Nicolas Bottan, Ian Coxhead, Andrew Clark, Yohanes Riyanto, Hitoshi Shigeoka, and the seminar participants at Keio University and Osaka University for their helpful comments, which substantially improved the paper. Any remaining errors are ours. The experiment and pre-analysis plan (PAP) were pre-registered in the American Economic Association RCT Registry (RCT ID: AEARCTR-0005772). The experiment was approved by the Review Board Ethics Committees of Kindai University, Japan (ID: ECON02-01). Declarations of interest: none.

${ }^{\dagger}$ Associate Professor (Specially Appointed). Center for Infectious Disease Education and Research (CiDER), Osaka University, D74-1 Office for Industry-University Co-Creation (Bldg. D), 2-1 Yamadaoka, Suita, Osaka, 565-0871 Japan. Email: kitamura@cider.osaka-u.ac.jp. Phone: +81 6-6879-8543.

${ }^{\ddagger}$ Professor. Faculty of Economics, Kindai University. 228-3, Shin-Kamikosaka, Higashi-Osaka city, 5770813 Japan. Email: kyamada@kindai.ac.jp. 


\section{Introduction}

The COVID-19 pandemic has threatened human lives and economic activities globally. Some countries have introduced strict nationwide lockdowns to curb the further spread of the coronavirus. Without strict lockdown measures or financial compensation for people to stay at home, governments would have been encouraging citizens to take their own restraint measures. However, a significant number of people have not complied with governments' self-quarantine requests (Bloomberg, 2020). This background encourages us to investigate the effects of information provision on cooperation with social distancing measures, using a randomized controlled trial (RCT) framework.

In this study, we make a novel contribution to the literature on changing behaviors by adopting a $2 \times 2$ factorial design to investigate the power of information provision. One way of guiding citizens with information is to allow them to compare their own behaviors with the social norms. The previous literature has shown that when people are informed about the social norms in regard to, e.g., movie ratings (Chen et al., 2010) and energy consumption (Allcott, 2011), they tend to follow them. ${ }^{1}$ We provide new evidence on how effective social comparisons can be in guiding citizens in the context of infectious diseases. In particular, we randomly inform participants of their past behaviors as well as those related to the social norms, thereby allowing them to make social comparisons.

In the other treatment arm of our experiment, we investigate the effect of the identity of the messenger. We anticipate that information becomes more powerful when conveyed

\footnotetext{
${ }^{1}$ Other examples include the effects of information treatments on donations (Frey and Meier, 2004), environmental protection behaviors (Goldstein et al., 2008), energy consumption (Costa and Kahn, 2013), job satisfaction (Card et al., 2012), worker performance (Cohn et al., 2014; Breza et al., 2017), support for income redistribution (Kuziemko et al., 2015), political campaign contributions (Perez-Truglia and Cruces, 2017), and location choices (Bottan and Perez-Truglia, 2018).
} 
by a powerful messenger than when delivered by a familiar face: if a series of information repeatedly comes from the same person or authority, people may begin to pay little attention to him/her; this is termed the burn-out effect (Eckel et al., 2007). ${ }^{2}$ In the same vein, Banerjee et al. (2020a) investigated the effectiveness of the voice of celebrity, the Nobel laureate Abhijit Banerjee in this case, compared with typical government messaging on health behaviors during the COVID-19 pandemic in India. ${ }^{3}$ In Japan, the most powerful voice is that of the Emperor. However, the Emperor rarely spoke about COVID-19 during the pandemic. As such, we anticipate that messages from the Emperor are more powerful than those from a typical government messenger. In our experiment, we examine the power of the messenger, by randomly changing the messengers in our information treatments.

A great advantage of this study, which exploits a $2 \times 2$ factorial design, is that we can examine if the effects of information on behaviors can be multiplied by exploiting two different manipulations at the same time. More concretely, we expect that the effects of social comparisons would be enhanced when information is delivered by the powerful messenger.

Our web-based RCT experiment with about 3,000 subjects was conducted in Japan immediately after a state of emergency was imposed on April 7, 2020 during the pandemic. Our primary outcome variable in the study is the time spent outside the home, which we denote by "outing time." We regard outing time as a proxy for cooperation with social distancing measures. We consider total outing time as well as outing time spent on unnecessary tasks. Here, necessary tasks include going to work, shopping for groceries, visiting hospital, and attending school.

\footnotetext{
${ }^{2}$ On a related note, Ajzenman et al. (2020) found that when Brazil's president, despite being a familiar face for citizens, suddenly changed the tone of his speeches in the midst of the COVID-19 pandemic, his supporters responded by changing their self-restraint behaviors.

${ }^{3}$ See also Bassi and Rasul (2017).
} 
Our findings are as follows. First, we find that our information manipulation, which showed our subjects that their outing time was longer than the social norms, made them more cooperative with social distancing measures. The effect sizes are in the range of $8-$ 26 percent compared with the control means. Second, we find no supportive evidence that powerful messenger can change behaviors more than the typical messenger, as opposed to our expectations. Moreover, we find that powerful messenger could derive so-called back-firing effects: one concern about providing information on the social norms is that those who had been cooperating with social distancing rules lost their discipline and ventured outside more after being informed of the social norms. Interestingly, we found that information that their outing time was shorter than the social norms did not change their behaviors when delivered by a typical government messenger, but it did so in a socially undesirable direction when delivered by the Emperor. This intriguing result could not be obtained without our $2 \times 2$ factorial design.

We also have a unique contribution in a practical perspective. In the study, our main outcome variables are self-reported, which raises some concerns. In order to check the validity of these outcome variables, we devised a new approach in the context of RCT experiments, and showed that our self-reported data should not dampen our results.

The rest of the paper is organized as follows. Section 2 explains our experimental settings and data. Section 3 shows our empirical results. Finally, Section 4 concludes. 


\section{Experimental Design}

The experiment and pre-analysis plan (PAP) were pre-registered in the American Economic Association RCT Registry. ${ }^{4}$ Moreover, the experiment is high-powered (minimum detectable effect $<0.2)$ based on our power calculation conducted in the PAP.

\subsection{Data Collection}

We conducted an online survey from April 17 to May 5, 2020 in Japan. Japan was an ideal setting in which to conduct such an experiment because it did not introduce a strict lockdown, and there was no legal enforcement against outings. The study period included the period in which the pandemic and its effects on society were severe and when a substantial proportion of the population in Japan was still going outside (Figure A.1 in the supplementary material).

To obtain a representative sample of the Japanese population, we recruited a local survey company, MyVoice Inc., to administer the experiment. The initial number of subjects was 3,493. Invitation emails were sent to pre-registered participants, aged 20 to 59 years and living in one of seven prefectures in Japan (Chiba, Fukuoka, Hyogo, Kanagawa, Osaka, Saitama, and Tokyo). ${ }^{5}$ We used stratified random sampling to ensure that the breakdown of our sample mirrored the national population in terms of age and gender, based on the Basic Resident Register in 2019.

Once subjects entered the study's website, they were informed that the survey was being

\footnotetext{
${ }^{4}$ RCT ID: AEARCTR-0005772. The experiment was approved by the Review Board Ethics Committees of Kindai University, Japan (ID: ECON02-01). All the analyses we proposed in the PAP are covered in an archived version of our paper (Kitamura and Yamada, 2020). Furthermore, we conducted analyses that were not planned in the PAP for the reason mentioned by Banerjee et al. (2020b).

5 The state of emergency was announced by the government for these seven prefectures on April 7 and was expanded to the other prefectures on April 16 (Figure A.1 in the supplementary material). We limited the sampling locations to these seven prefectures to control for the baseline conditions. We had no idea that the state of emergency would be extended to the other prefectures when the experiment was designed.
} 
conducted for academic research and that the confidentiality of their answers was ensured. They were also informed that they were expected to answer eight surveys for three weeks. The number of questions in each survey, the expected time it would take to complete the survey, and our payment scheme (i.e., participation rewards to encourage them to complete all the surveys) were also made clear. Upon completing all the surveys, they could earn up to 180 JPY (about 2 USD). We set these participation rewards following advice from MyVoice Inc. The following subsections explain our series of surveys in chronological order. We provide the original survey questionnaire as well as its English translations in the supplementary material.

\subsubsection{April 17: Survey of demographic characteristics}

Our first survey included demographic questions regarding gender, age, education, marital status, the number of people living together, residential location, employment status, selfreported health status, household pre-tax annual income, and negative income shock. In addition, to understand the mechanism of the effects of the information treatments on outing time, if any, we included questions to measure time preferences, risk preferences, social preferences, the tendency to exhibit herd behavior, political interests, political preferences, policy evaluations, religious beliefs, and national identity. Our questions that intended to elicit economic preferences were borrowed from Sutter et al. (2018) and Falk et al. (2018). Other questions on personality traits were borrowed from the International Social Survey Programme and World Values Survey when available. Finally, we asked what types of mobile/smartphones survey participants used. This information was used for our follow-up study to check the validity of our main outcome variable. 


\subsubsection{April 18 and 19: Pre-treatment surveys (Week 1)}

We collected data on self-reported weekend outing times to measure the baseline outing behaviors of our subjects. We used the sum of outing time for both Saturday and Sunday to construct individually tailored information, which was used in the randomized information treatments explained below.

We devised our survey questions on self-reported outing time over weekends carefully to minimize respondents' resistance to providing answers. First, we repeatedly stated that the research was purely for academic purposes to understand human behaviors and that we were in no position to judge our respondents' morals. Second, we asked about total outing time and the proportion of outing time spent on necessary activities. ${ }^{6}$ We then computed outing time spent on unnecessary activities by subtracting outing time spent on necessary activities from total outing time. In the following section, we investigate the effects of the information treatments on total outing time as well as outing time spent on unnecessary activities. ${ }^{7}$ For example, the exact phrasing used to collect the data on outing time for April 18 read:

Q1. How much time did you spend outside your home on April 18th, Saturday?

Please provide the total amount of time you spent outside of your home.

* If you did not leave your house, please answer "0 hours 0 minutes."

Q2. Of which, how much time in total did you spend outside your home on activities essential to daily life (e.g., shopping for daily necessities, traveling to school, traveling to work, traveling to the hospital, etc.)?

If you had more than one purpose for a single outing, please separate the time

\footnotetext{
${ }^{6}$ Researchers directly asking about outing time spent on unnecessary activities might face resistance.

7 The follow-up survey showed that respondents were equally honest in reporting their outing time across treatment conditions, as explained in Section 3.4.
} 
you spent for each and answer with the total amount of time spent on what you feel is necessary for daily life.

* If you only left your home for matters essential to daily life, please answer the same as in Q1.

\subsubsection{April 23: Randomized information treatments}

Our randomized information treatments were conducted on April 23. In the survey, we first collected respondents' expectations about their outing behaviors relative to those of others in Week 1 (these were used to test the potential mechanism as well). We then showed respondents randomly assigned pieces of information. Finally, immediately after the information provision session, we collected data on their intention to cooperate with social distancing measures.

To ensure that subjects were actually exposed to the randomly assigned information treatment before the start of the post-treatment surveys, the window of the information provision session closed on April 24. Those who did not respond before April 24 were dropped from our study sample, as explained below.

\subsubsection{April 25 and 26 (Week 2), May 2 and 3 (Week 3): Post-treatment surveys}

To measure the responses to our information treatments, we collected data on outing time for two weekends. These pieces of information constitute our main outcome variables in the research. The procedures and phrases were the same as in the pre-treatment survey. We monitored subjects for two weekends to investigate the lasting effects of the information treatments. Subjects might not have reacted to our treatments immediately, especially if 
their plans on the weekend immediately after the interventions were already set when the treatments were applied. In that case, it would take more time for our treatments to show effects. We chose a combined outing time for Weeks 2 and 3 for the main analyses below.

Table A.1 in the supplementary material provides the summary statistics of the collected data.

\subsection{Design of the Randomized Information Treatments}

Of the approximately 3,500 respondents, about 875 participants were randomly assigned to each of the four treatment arms. Two conditions focused on the introduction of social comparisons to the information (horizontal direction in Figure 1) and two conditions focused on the sender of the information: then-Prime Minister Shinzo Abe as a typical government messenger and Emperor Naruhito (vertical direction in Figure 1).

In all four conditions, participants received the same message on the ongoing problems regarding COVID-19 and were told that their behaviors and decisions would affect whether the pandemic would abate soon. To enhance the salience of the experiment, we chose actual statements made by the Prime Minister and Emperor. Further, to balance the cognitive burden needed to understand the messages, we controlled for the word counts of the messages between the two conditions.

First, we examined the potential effects of comparing individuals' behaviors with the so-

cial norms. Half our participants - those in Groups B (GOV:feedback) and D (EMP:feedback) in Figure 1-received information on weekend outing time to enable social comparisons. These pieces of information, highlighted in red in the figure, showed their weekend outing time over the previous weekend (April 18 and 19, Week 1) together with the median value 
Figure 1: Experimental Design

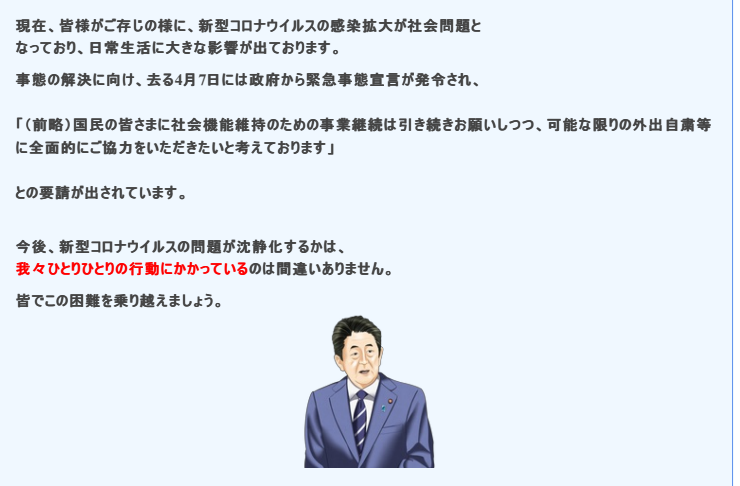

(a) Group A

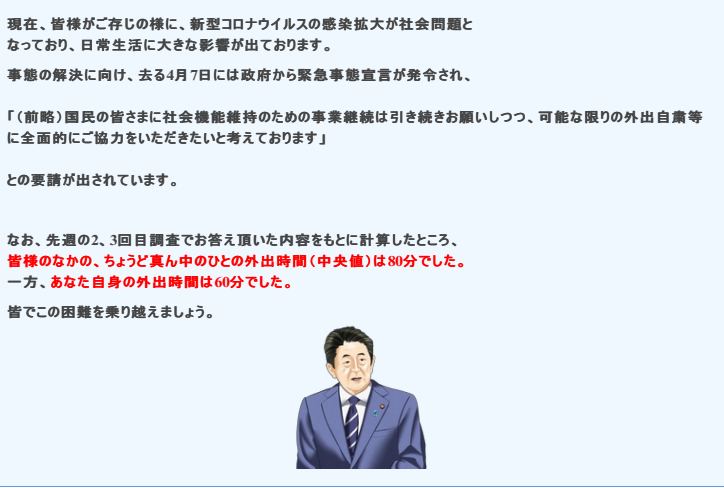

(b) Group B

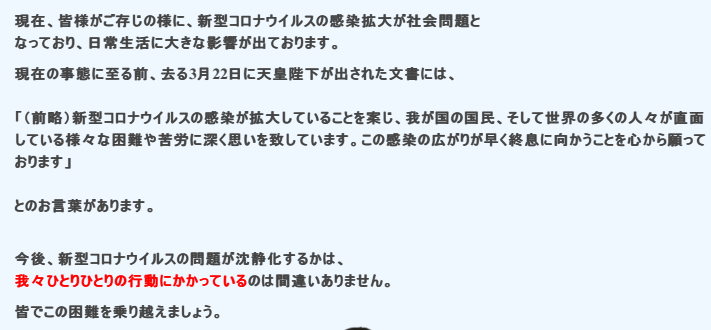

(c) Group C

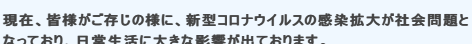

てつており、日常生活に大きな影䈉が出ております。

現在の事態に至る前、去る3月22日に天皇阵下が出された文書には、

「(前略) 新型コロナウイルスの感染が拡大していることを案し、我が国の国民、そして世界の多くの人々が直面

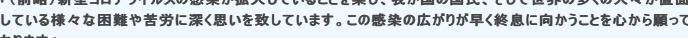
おりま」

とのお言葉があります。

なお、先異の2、3回目調查でお答え頂いた内容をもとに計算したところ、

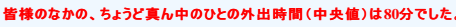

一方、あなた自身の外出時間は60分でした。

皆でこの困蜼を乘り越えましうう。

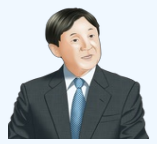

(d) Group D

Note. Examples of our information treatments are shown. Groups A and B receive messages from the Prime Minister, while Groups C and D receive messages from the Emperor. Those messages share the basic concepts of efforts to overcome the COVID-19 pandemic. In addition to the basic concept, those in Groups $\mathrm{B}$ and $\mathrm{D}$ receive tailored information about each individual's relative outing time on the previous weekend in the same prefecture. 
of the same information for all the participants in the same prefecture. ${ }^{8}$ By contrast, participants in Groups A (GOV:no feedback) and C (EMP:no feedback) in Figure 1 received messages that contained no ability to make social comparisons.

Second, we manipulated the senders of the information. In Groups A (GOV:no feedback) and B (GOV:feedback), the sender was the Prime Minister. We considered these conditions as our control conditions since, in the real world, COVID-19-related messages are usually provided by political leaders. In Groups C (EMP:no feedback) and D (EMP:no feedback), participants received messages from Emperor Naruhito. These messages came with images of the messengers to enhance the reality of the experiment.

Lastly, in our experimental setting, it was crucial for us to test the heterogeneous responses caused by different standpoints on the distributions of weekend outing time. In the PAP, we hypothesized that subjects whose outing time in Week 1 was above the median value (AB group) would be more likely to refrain from outings after they acknowledged their relative standing. By contrast, we anticipated that subjects whose outing time in Week 1 was below or equal to the median value (BE group) would be less likely to refrain from outings. Such information could even increase weekend outing time after our treatments due to the effects of "moral license," the occurrence of which would be denoted as an example of the back-firing effects of information provision.

\subsection{Study Sample and Balance Checks}

Before presenting our empirical results, we explain how our study sample was derived and verify whether the randomization was correctly performed. Of our initial 3,493 participants,

\footnotetext{
${ }^{8}$ Since the weather conditions differed across prefectures at the time of the experiment, we let these median values be different across prefectures to take into account differences in weather conditions.
} 
we dropped respondents who did not receive randomly assigned information treatments (188) and those who did not provide all their post-treatment outing time (247). Finally, we dropped respondents who did not pass the attention question in our information treatment survey (190). The final sample had 2,868 participants (82.1 percent of the original sample).

As we documented in our PAP, we conducted balance checks over the variables of gender, age, education, marital status, per capita household income, negative income shock, and residential location. While we did not include the baseline outing time in Week 1 in our PAP, we also checked its balance. Table A.2 in the supplementary material shows that all the variables are balanced at a false discovery rate of 0.05 except for the indicator of negative income shock. To control for the potential effects stemming from the imbalance of this variable, we included it in the subsequent analyses.

In addition, since the information content necessarily differs by treatment group, a common concern was that attrition might also differ across groups. After respondents received the information treatments, 247 of the 3,305 subjects did not complete all the surveys, as mentioned above. When we regressed an attrition dummy on the treatment dummies and demographic variables, we found that attrition in Group C (EMP:no feedback) was higher than that in Group A (GOV:no feedback) $(p=0.092)$, which could be a concern (Table A.3 in the supplementary material). However, since 52 subjects from Group A and 70 subjects from Group C dropped out of the survey, this difference does not seem to have quantitative implications (Table A.4 in the supplementary material). At the very least, our study sample is balanced, as already stated. Hence, attrition was not an issue in the subsequent analyses. 


\section{Causal Effects of the Information Treatments}

\subsection{Empirical Specifications}

Using an RCT experiment, our empirical specification for investigating the manipulation effects is simple. When we treat Group A (GOV:no feedback) as the omitted category, our empirical specification reads:

$$
\begin{aligned}
& Y_{i}^{k}=\varphi_{1}^{k} \text { GOV_Feedback_Above }{ }_{i}+\varphi_{2}^{k} \text { GOV_Feedback_BelowEq }_{i} \\
& +\varphi_{3}^{k} E_{\text {EMP_NoFeedback_Above }}+\varphi_{4}^{k} \mathrm{EMP}_{-} \text {NoFeedback_BelowEq }_{i} \\
& +\varphi_{5}^{k} \text { EMP_Feedback_Above }_{i}+\varphi_{6}^{k} \text { EMP_Feedback_BelowEq }_{i}+X_{i}^{\prime} \Gamma^{k}+\phi_{p}^{k}+\varepsilon_{i}^{k},
\end{aligned}
$$

where $i$ denotes the individuals, and $Y_{i}^{k}$ is outcome $k \in\{1,2\}$. Our outcome variables are individuals' outing time from the post-treatment surveys; total outing time $(k=1)$ and time spent on unnecessary activities $(k=2) .{ }^{9} \quad$ GOV_Feedback_Above $e_{-}\left(G O V_{-}\right.$Feedback_BelowE $\left.q_{i}\right)$ is an indicator meaning that those subjects were in Group B (GOV:feedback) and that their outing time in Week 1 was above (below or equal to) the median value for the prefecture, EMP_NoFeedback_Above ${ }_{i}\left(E M P_{-} N_{o} F_{e e d b a c k} B_{-}\right.$Nelow $\left.q_{i}\right)$ is an indicator meaning that those subjects were in Group C (EMP:no feedback) and that their outing time in Week 1 was above (below or equal to) the median value for the prefecture, EMP_Feedback_Above ${ }_{i}$ $\left(E M P_{-}\right.$Feedback_BelowE $\left.q_{i}\right)$ is an indicator meaning that those subjects were in Group D (EMP:feedback) and that their outing time in Week 1 was above (below or equal to) the

\footnotetext{
${ }^{9}$ Results on intentions are reported in our supplementary material.
} 
median value for the prefecture, $X_{i}$ is a vector consisting of outing time in Week 1 , an indicator of a negative income shock, and an indicator of above-median outing time, $\phi_{p}^{k}$ is the prefecture fixed effects, and $\varepsilon_{i}^{k}$ is the error term. We take into account the baseline outing time in Week 1 for Group C (EMP:no feedback), thereby allowing us to compare the effect sizes of the manipulations in similar groups of individuals in terms of outing time in Week 1 (Above median and Below or equal in Table 1). Finally, we use robust standard errors to account for heteroskedasticity. Table A.5 in the supplementary material shows the regression results, and we use the coefficients for evaluating the effect sizes of the treatments in the next section.

\subsection{Main Results}

First, Panels A and B in Table 1 summarize the effect of information manipulations about social comparisons. We compare the outing time in Weeks 2 and 3 (combined) between subjects with similar outing time in Week 1 . In the table, we also report the p-values from the randomization inference in brackets (Young, 2019). We conduct randomization inference because of the possible concern about multiple outcome variables and treatment variables, and our criterion of the manipulation effects being statistically significant in this study is that the p-values from the randomization inference are below 0.10 .

Panel A, GOV condition, shows the treatment effect of being informed versus not informed about own outing time during Week 1 when the messenger is a typical government one. The left column of Panel A in Table 1 shows that compared with the control mean of 665 minutes, giving feedback significantly reduces total outing time by 8 percent of the control mean for those whose outing time during the first week was above the median value. 
By contrast, the right column of the same panel shows that unnecessary outing time was not affected by the treatment, which implies that necessary outing time, such as time for daily necessities shopping, was reduced among subjects in the AB group. We did not find significant effects among subjects in the BE group in the same condition.

Next, Panel B, EMP condition, replicates the analysis in Panel A but the messenger is the Emperor. The left column of the panel shows that total outing time was not affected by the treatment, while the right column shows that compared with the control mean of 159 minutes, giving feedback significantly reduces unnecessary outing time by 26 percent for those whose outing time during the first week was above the median value.

In summary, we find that our manipulation, which showed our subjects that their outing time was longer than the social norms, made them more cooperative with social distancing measures regardless of the messengers. The effect sizes of the manipulation of informing the social norms are in the range of 8-26 percent compared with the control means. ${ }^{10}$

\footnotetext{
${ }^{10}$ We can compare the effect size of our results with that in the other studies mentioned in the Introduction. First, Frey and Meier (2004) found that informing students that many other students contributed to charitable funds in the past increased the probability of contributions to the funds by 6 percent. Second, Goldstein et al. (2008) showed that informing hotel room guests that many other guests joined the towel reuse program in the past increased the reuse of towels by 26 percent. Third, Allcott (2011) found that providing residential utility consumers with information about their neighbors' energy consumption reduced those who consume more by 2 percent. Finally, Chen et al. (2010) provided evidence that informing the median user's total number of movie ratings changed the number of ratings for those below the median value by 530 percent and for those above the median value by 62 percent. Although the outcome, treatment, and context are different, the effect size in our experiment is in line with those of these studies, with the exception of Chen et al. (2010).
} 
Table 1: Summary of the Treatment Effects

\begin{tabular}{|c|c|c|c|c|c|c|c|}
\hline \multirow[b]{2}{*}{ Comparison } & \multirow{2}{*}{$\begin{array}{l}\text { Outing time } \\
\text { in Week } 1\end{array}$} & \multicolumn{3}{|c|}{ Total outing time (min) } & \multicolumn{3}{|c|}{ Unnecessary outing time (min) } \\
\hline & & Diff. & Ctrl. mean & Effect size & Diff. & Ctrl. mean & Effect size \\
\hline \multirow{3}{*}{ Panel $A$} & \multirow{3}{*}{ Above median } & -53.430 & & & -9.662 & & \\
\hline & & $(34.844)$ & 665.018 & $8 \%$ & $(19.921)$ & 140.108 & $7 \%$ \\
\hline & & {$[0.067]^{*}$} & & & {$[0.524]$} & & \\
\hline \multirow{3}{*}{$\begin{array}{l}\text { Group B - A } \\
\text { (GOV cond.) }\end{array}$} & \multirow{3}{*}{ Below or equal } & 7.601 & & & -9.035 & & \\
\hline & & $(24.529)$ & 155.333 & $5 \%$ & $(10.169)$ & 42.745 & $21 \%$ \\
\hline & & {$[0.780]$} & & & {$[0.510]$} & & \\
\hline \multirow{3}{*}{ Panel B } & \multirow{3}{*}{ Above median } & -7.283 & & & -41.882 & & \\
\hline & & $(35.611)$ & 629.898 & $1 \%$ & $(19.413)^{* *}$ & 159.295 & $26 \%$ \\
\hline & & {$[0.809]$} & & & {$[0.007]^{* * *}$} & & \\
\hline \multirow{3}{*}{$\begin{array}{l}\text { Group D - C } \\
(\text { EMP cond.) }\end{array}$} & \multirow{3}{*}{ Below or equal } & 50.772 & & & 3.985 & & \\
\hline & & $(17.469)^{* * *}$ & 129.403 & $39 \%$ & $(7.502)$ & 33.523 & $12 \%$ \\
\hline & & {$[0.065]^{*}$} & & & {$[0.773]$} & & \\
\hline \multirow{3}{*}{ Panel $C$} & \multirow{3}{*}{ Above median } & -28.993 & & & 19.409 & & \\
\hline & & $(35.110)$ & 665.018 & $4 \%$ & $(20.327)$ & 140.108 & $14 \%$ \\
\hline & & {$[0.330]$} & & & {$[0.192]$} & & \\
\hline \multirow{3}{*}{$\begin{array}{l}\text { Group C - A } \\
\text { (No feedback cond.) }\end{array}$} & \multirow{3}{*}{ Below or equal } & -23.531 & & & -9.241 & & \\
\hline & & $(16.672)$ & 155.333 & $16 \%$ & $(9.024)$ & 42.745 & $22 \%$ \\
\hline & & {$[0.383]$} & & & {$[0.506]$} & & \\
\hline \multirow{3}{*}{ Panel D } & \multirow{3}{*}{ Above median } & 17.154 & & & -12.811 & & \\
\hline & & $(35.210)$ & 626.759 & $3 \%$ & $(18.977)$ & 131.362 & $10 \%$ \\
\hline & & {$[0.555]$} & & & {$[0.410]$} & & \\
\hline \multirow{3}{*}{$\begin{array}{l}\text { Group D - B } \\
\text { (Feedback cond.) }\end{array}$} & \multirow{3}{*}{ Below or equal } & 19.641 & & & 3.778 & & \\
\hline & & $(25.000)$ & 161.824 & $12 \%$ & $(8.859)$ & 33.963 & $11 \%$ \\
\hline & & {$[0.458]$} & & & {$[0.805]$} & & \\
\hline
\end{tabular}

Note. Robust standard errors are in parentheses and randomization p-values are in brackets. The randomization- $t$ method was used to compute the randomization p-values where three outcome variables and six treatment variables (excluding the omitted category) were taken into account. The number of randomization iterations was 2,000 and all the regressions included control variables (Young, 2019). Each coefficient and standard errors were obtained by regressing outing time on the treatment variables and control variables. The control variables are outing time in Week 1 , an indicator of a negative income shock, and the prefecture fixed effects. For the values for the GOV condition, the estimation results in columns (1) and (2) of Table A.5 were used. For the values for the EMP condition, the estimation results in columns (5) and (6) of the same table were used. For the values for the No feedback condition, the estimation results in columns (1) and (2) of Table A.5 were used. For the values for the Feedback condition, the estimation results in columns (3) and (4) of the same table were used. ${ }^{*}, * *$, and $* * *$ indicate $p<0.10, p<0.05$, and $p<0.01$, respectively. 
It is interesting that, as shown in Panel B, the treatment significantly increased the total outing time of individuals whose outing time was below or equal to the median value, while keeping their unnecessary outing time unaffected, by 39 percent from the control mean of 129 minutes. Although the back-firing effect of information feedback was expected, the fact that we only found it in the EMP condition was unexpected. We will investigate the potential mechanism further below (Section 3.3).

Second, Panels C and D in Table 1 summarize the effect of the powerful messenger. As in Panels A and B, we compare the outing time in Weeks 2 and 3 (combined) between subjects with similar outing time in Week 1. Panel C, No feedback condition, compares Group A (GOV:no feedback) with Group D (EMP:no feedback); hence, no participants were informed about their outing time in this comparison. By contrast, Panel D, Feedback condition, compares Group B (GOV:feedback) with Group D (EMP:feedback); here, all participants were informed about their outing time. Contrary to our expectations about the power of the messenger, we found no significant effects of changing outing behaviors. This is in sharp contrast to the results from India (Banerjee et al., 2020a), which show the significant effects of the voice of celebrity.

\subsection{Potential Mechanism}

Next, using information on respondents' personality traits, we investigate the potential mechanism behind the findings shown in the previous subsections.

First, we investigate the potential mechanism for the cases in which we obtained the socially desirable result of a reduction in outing time: GOV:feedback $\times$ above median for total outing time and EMP:feedback $\times$ above median for unnecessary outing time. Among 
the covariates obtained in the baseline survey, we focus on the following three variables; respondents' prior optimistic beliefs about their relative standing in the distribution of outing behaviors, altruistic preferences, and tendency to exhibit herd behavior. Second, we check which factor might drive the undesirable back-firing effect of the EMP:feedback $\times$ below or equal condition on total outing time. In this case, our variables of interest are political preferences, policy evaluations, and national identity. 
Table 2: Heterogeneous Effects Based on Personality Traits

\begin{tabular}{|c|c|c|c|c|c|c|c|c|c|}
\hline & \multicolumn{9}{|c|}{ Dependent variable: } \\
\hline & \multicolumn{3}{|c|}{ Total outing time $(\min )$} & \multirow{2}{*}{\multicolumn{3}{|c|}{$\begin{array}{c}\text { Unnecessary outing time }(\mathrm{min}) \\
\text { Personality traits: }\end{array}$}} & \multicolumn{3}{|c|}{ Total outing time (min) } \\
\hline & & & & & & & & & \\
\hline & $\begin{array}{l}(1) \\
\text { Opti. Prior }\end{array}$ & $\begin{array}{l}(2) \\
\text { Altruistic }\end{array}$ & $\begin{array}{l}(3) \\
\text { Herd Behav. }\end{array}$ & $\begin{array}{l}(4) \\
\text { Opti. Prior }\end{array}$ & $\begin{array}{l}(5) \\
\text { Altruistic }\end{array}$ & $\begin{array}{l}(6) \\
\text { Herd Behav. }\end{array}$ & $\begin{array}{l}(7) \\
\text { Polt. Pref. }\end{array}$ & $\begin{array}{l}(8) \\
\text { Poli. Eval. }\end{array}$ & $\begin{array}{l}(9) \\
\text { Natl. }\end{array}$ \\
\hline $\begin{array}{l}\text { GOV:feedback } \times \text { above median } \times \text { personality } \\
\text { traits }\end{array}$ & $\begin{array}{l}130.247 \\
(74.806)^{*} \\
{[0.030]^{* *}}\end{array}$ & $\begin{array}{r}-90.971 \\
\\
(71.469) \\
{[0.121]}\end{array}$ & $\begin{array}{r}-116.591 \\
(69.153)^{*} \\
{[0.047]^{* *}}\end{array}$ & & & & & & \\
\hline $\begin{array}{l}\text { EMP:feedback } \times \text { above median } \times \text { personality } \\
\text { traits }\end{array}$ & & & & $\begin{array}{r}-38.459 \\
(41.095) \\
{[0.193]}\end{array}$ & $\begin{array}{r}36.239 \\
(38.905) \\
{[0.241]}\end{array}$ & $\begin{array}{r}34.580 \\
(40.890) \\
{[0.278]}\end{array}$ & & & \\
\hline $\begin{array}{l}\text { EMP:feedback } \times \text { below or equal } \times \text { personal- } \\
\text { ity traits }\end{array}$ & & & & & & & $\begin{array}{r}42.762 \\
(47.541) \\
{[0.362]}\end{array}$ & $\begin{array}{r}8.138 \\
(35.147) \\
{[0.857]}\end{array}$ & $\begin{array}{r}6.885 \\
\\
(34.726) \\
{[0.908]}\end{array}$ \\
\hline $\begin{array}{l}\text { other treatment variables } \\
\text { controls }\end{array}$ & $\begin{array}{l}\text { yes } \\
\text { yes }\end{array}$ & $\begin{array}{l}\text { yes } \\
\text { yes }\end{array}$ & $\begin{array}{l}\text { yes } \\
\text { yes }\end{array}$ & $\begin{array}{l}\text { yes } \\
\text { yes }\end{array}$ & $\begin{array}{l}\text { yes } \\
\text { yes }\end{array}$ & $\begin{array}{l}\text { yes } \\
\text { yes }\end{array}$ & $\begin{array}{l}\text { yes } \\
\text { yes }\end{array}$ & $\begin{array}{l}\text { yes } \\
\text { yes }\end{array}$ & $\begin{array}{l}\text { yes } \\
\text { yes }\end{array}$ \\
\hline $\begin{array}{l}\mathrm{R}^{2} \\
\mathrm{~N}\end{array}$ & $\begin{array}{l}0.50 \\
2868\end{array}$ & $\begin{array}{l}0.49 \\
2868\end{array}$ & $\begin{array}{l}0.49 \\
2868\end{array}$ & $\begin{array}{l}0.08 \\
2868\end{array}$ & $\begin{array}{l}0.08 \\
2868\end{array}$ & $\begin{array}{l}0.08 \\
2868\end{array}$ & $\begin{array}{l}0.49 \\
2868\end{array}$ & $\begin{array}{l}0.49 \\
2868\end{array}$ & $\begin{array}{l}0.49 \\
2868\end{array}$ \\
\hline
\end{tabular}

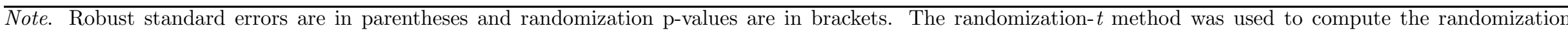

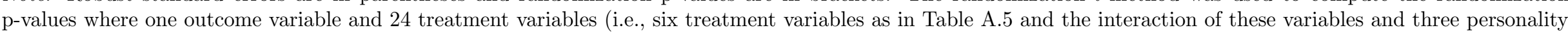

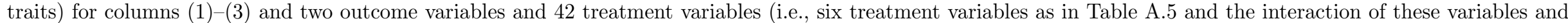

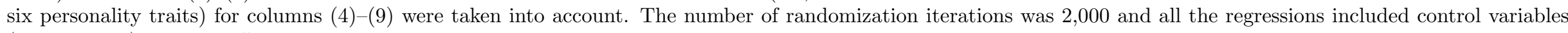

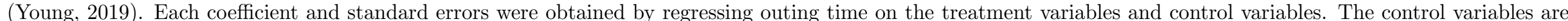

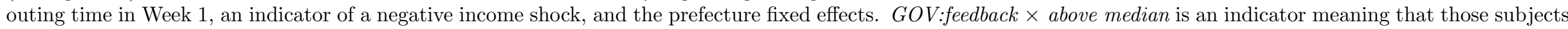

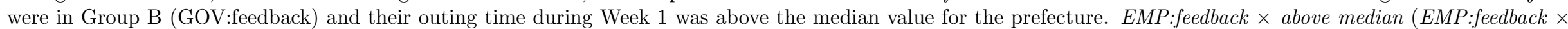

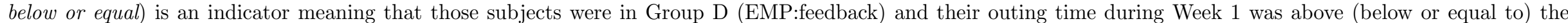

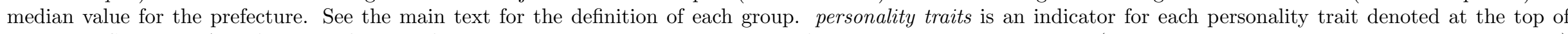

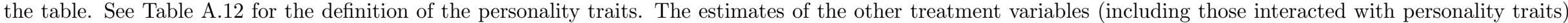

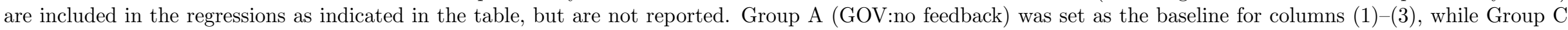
(EMP:no feedback) was set as the baseline for the remaining columns. ${ }^{*}$, **, and ${ }^{* * *}$ indicate $p<0.10, p<0.05$, and $p<0.01$, respectively. 
Table 2 reports the results. Regarding the effect of GOV:feedback $\times$ above median on total outing time, we found that an optimistic prior belief about the baseline standing point of outing time negates the effects of the manipulations, as reflected in the positive and significant estimate (column (1)), and that those who tend to exhibit herd behaviors cooperate more after the information feedback (column (3)). These effects are significant after Young's randomization inference. We did not find any significant driving forces regarding unnecessary outing time in the EMP condition (columns (4)-(6)).

Regarding the potential driving force of the back-firing effects shown in columns (7)-(9), somewhat unexpectedly, plausible variables such as political preferences, policy evaluations, and national identity did not explain them. ${ }^{11}$ Other results on the tests of potential mechanisms can be found in the archived version of the paper (Kitamura and Yamada, 2020) in which we found that there were no substantial heterogeneity with respect to the other personality traits. As such, we suggest that back-firing effects among Japanese citizens were rather universal. Given the results here and those in Banerjee et al. (2020a), we argue that the effects of celebrity voices depend on the context and that policymakers should be careful of choosing messengers.

\subsection{Robustness of the Main Findings}

\subsubsection{Validity of our outcome variables}

As our measures of outing time are self-reported, to minimize concerns arising from the nature of these outcome variables, we devised unique two-stage follow-up surveys, the first step of which was launched on May 22, to check the validity of self-reported outing time using

\footnotetext{
${ }^{11}$ The results were robust regardless of how we constructed these variables.
} 
smartphones. The pre-installed app called Healthcare on iPhones records a user's step count and distance traveled per day. ${ }^{12}$ Using information from the baseline survey, we identified 1,146 iPhone users and asked them to provide screenshots of their step count and distance traveled in the Healthcare app for the days of their reported outing time.

Our presumption here is that if individuals reported the wrong information on their outing time in our surveys, they would be more reluctant to provide us with their screenshots because researchers would detect the inconsistency of their responses. Thus, if willingness to participate in the follow-up survey is systematically different across the treatment groups, it would suggest that our estimates are biased. In addition, if the individuals in the treatment group who report longer or shorter outing times are less likely to cooperate than those in the control group, it would also suggest biases in our estimates. In the first stage of our follow-up survey, we asked respondents about their willingness to participate. In the second stage, we randomly chose willing volunteers and asked them to submit their screenshots. ${ }^{13}$ The reward for providing us with screenshots was 200 JPY, greater than the amount that they received for completing all eight of the earlier surveys. This is a sufficiently high reward to motivate them to provide screenshots as long as they reported their outing time honestly.

Using the data from the first stage of our follow-up surveys, we regress a dummy of willingness to provide screenshots on various variables. In column (1) in Table 3, the variables

\footnotetext{
${ }^{12}$ For Android phones, a similar app, Google Fit, was not pre-installed until the latest version of Android 10.0. At the time of our experiment, the circulation rate of Android 10.0 was well below 10 percent. Therefore, we focused on iPhone users in our follow-up surveys.

${ }^{13}$ Although we could not cover all 516 willing volunteers because of the shortage of research funds, we conducted this second-stage survey for 118 respondents to avoid deception. Table A.6 and Figure A.2 in the supplementary material report the results using the information from these 118 respondents. Table A.6 shows that while we failed to replicate the significant results of the information feedback condition because of the smaller sample size, the sign of the estimates indicates that explaining the social norm made our respondents reduce their outing time. Moreover, the effect size (9 percent) is similar to those using selfreported measures. Figure A.2 shows that our self-reported outing time and data on distance travelled from the screenshots show a strong positive correlation $(\rho=0.59)$.
} 
Table 3: Validity of the Self-reported Outcome Variables

\begin{tabular}{|c|c|c|c|c|}
\hline & \multicolumn{4}{|c|}{ Dependent variable: Willingness to participate } \\
\hline & $(1)$ & $(2)$ & $(3)$ & (4) \\
\hline GOV:feedback & $\begin{array}{c}-0.055 \\
(0.046) \\
{[0.231]}\end{array}$ & $\begin{array}{c}-0.055 \\
(0.046) \\
{[0.235]}\end{array}$ & $\begin{array}{c}-0.055 \\
(0.046) \\
{[0.249]}\end{array}$ & $\begin{array}{c}-0.053 \\
(0.046) \\
{[0.254]}\end{array}$ \\
\hline GOV:feedback $\times$ outing time & & & $\begin{array}{c}0.047 \\
(0.040) \\
{[0.291]}\end{array}$ & $\begin{array}{c}0.041 \\
(0.041) \\
{[0.342]}\end{array}$ \\
\hline EMP:no feedback & $\begin{array}{l}0.043 \\
(0.046) \\
{[0.337]}\end{array}$ & $\begin{array}{c}0.032 \\
(0.046) \\
{[0.492]}\end{array}$ & $\begin{array}{c}0.043 \\
(0.045) \\
{[0.350]}\end{array}$ & $\begin{array}{c}0.032 \\
(0.046) \\
{[0.487]}\end{array}$ \\
\hline EMP:no feedback $\times$ outing time & & & $\begin{array}{c}0.073 \\
(0.041)^{*} \\
{[0.104]}\end{array}$ & $\begin{array}{c}0.043 \\
(0.042) \\
{[0.347]}\end{array}$ \\
\hline EMP:feedback & $\begin{array}{c}-0.009 \\
(0.047) \\
{[0.860]}\end{array}$ & $\begin{array}{c}-0.002 \\
(0.047) \\
{[0.958]}\end{array}$ & $\begin{array}{c}-0.008 \\
(0.047) \\
{[0.872]}\end{array}$ & $\begin{array}{c}-0.001 \\
(0.047) \\
{[0.987]}\end{array}$ \\
\hline EMP:feedback $\times$ outing time & & & $\begin{array}{c}0.032 \\
(0.050) \\
{[0.509]}\end{array}$ & $\begin{array}{c}0.016 \\
(0.050) \\
{[0.737]}\end{array}$ \\
\hline Outing time & & & $\begin{array}{c}-0.003 \\
(0.031)\end{array}$ & $\begin{array}{c}0.016 \\
(0.032)\end{array}$ \\
\hline controls & no & yes & no & yes \\
\hline $\begin{array}{l}\mathrm{R}^{2} \\
\mathrm{~N}\end{array}$ & $\begin{array}{c}0.01 \\
920\end{array}$ & $\begin{array}{c}0.05 \\
920\end{array}$ & $\begin{array}{c}0.01 \\
920\end{array}$ & $\begin{array}{c}0.06 \\
920\end{array}$ \\
\hline
\end{tabular}

Note. Robust standard errors are in parentheses and randomization p-values are in brackets. The sample is restricted to iPhone users. The randomization- $t$ method was used to compute the randomization p-values where one outcome variable and three treatment variables for columns (1) and (2) and one outcome variable and six treatment variables for columns (3) and (4) were taken into account. The number of randomization iterations was 2,000 (Young, 2019). Each coefficient and standard errors were obtained by regressing an indicator that takes one for those willing to provide screenshots and zero otherwise on only the treatment variables in columns (1) and (3) and on the treatment variables and control variables in columns (2) and (4). Control variables are gender, age, education, marital status, household pre-tax annual income, an indicator of a negative income shock, and the prefecture fixed effects. Each regression was run separately. Group A (GOV:no feedback) was set as the baseline. See the main text for the definition of each group. $*, * *$, and ${ }^{* * *}$ indicate $p<0.10, p<0.05$, and $p<0.01$, respectively. 
include only three treatment variables (omitted: Group A); in column (2), we also include individual characteristics. In columns (3) and (4) in the same table, we add self-reported outing time for all the weeks (i.e., Weeks 1-3) and the interaction terms between outing time and the treatment variables. We also report the randomization p-values from Young's randomization inference.

As shown in Table 3, none of our treatment variables in columns (1) and (4) are statistically significant, implying that participants were generally honest when they reported their outing time. These results confirm that our outcome variables of self-reported outing time are valid.

\subsubsection{Experimenter demand effects}

The self-reported nature of outing time can bring about another source of concern since our subjects might have reported their outing time under the influence of experimenter demand effects (Zizzo, 2010). In this study, such effects could have emerged when subjects received feedback that their outing time was longer than the social norm in a way that they would report shorter than the actual outing time in the following surveys no matter what their real outing time was.

One way of mitigating such a concern is to examine the potential heterogeneous effects of the manipulations (de Quidt et al., 2018). Specifically, we checked if there were differences in self-reported outing time between those willing to provide screenshots and those not among individuals whose outing time was above the median value. The idea is that those who misreported outing time would be unwilling to participate in the follow-up survey for fear of their misreporting being revealed. Thus, if we find that outing time is systematically 
Table 4: Experimenter Demand Effects

\begin{tabular}{|c|c|c|}
\hline & \multicolumn{2}{|c|}{$\begin{array}{c}\text { Dependent variable: } \\
\text { Outing time }\end{array}$} \\
\hline & (1) Total & (2) Unnec. \\
\hline Feedback $($ pooled $) \times$ above median & $\begin{array}{r}-49.977 \\
(72.164) \\
{[0.374]}\end{array}$ & $\begin{array}{r}-16.327 \\
(37.262) \\
{[0.567]}\end{array}$ \\
\hline Feedback $($ pooled $) \times$ above median $\times$ participate & $\begin{array}{r}48.990 \\
(90.072) \\
{[0.488]}\end{array}$ & $\begin{array}{r}-10.459 \\
(46.811) \\
{[0.781]}\end{array}$ \\
\hline Feedback $($ pooled $) \times$ below or equal & $\begin{array}{c}44.259 \\
(28.761) \\
{[0.350]}\end{array}$ & $\begin{array}{c}11.467 \\
(10.788) \\
{[0.643]}\end{array}$ \\
\hline Feedback $($ pooled $) \times$ below or equal $\times$ participate & $\begin{array}{r}-2.223 \\
(43.482) \\
{[0.972]}\end{array}$ & $\begin{array}{r}0.485 \\
(19.489) \\
{[0.986]}\end{array}$ \\
\hline above median & $\begin{array}{l}106.516 \\
(58.094)^{*}\end{array}$ & $\begin{array}{l}65.621 \\
(28.361)^{* *}\end{array}$ \\
\hline participate & $\begin{array}{l}54.276 \\
(23.189)^{* *}\end{array}$ & $\begin{array}{l}20.575 \\
(10.647)^{*}\end{array}$ \\
\hline above median $\times$ participate & $\begin{array}{c}-36.256 \\
(66.837)\end{array}$ & $\begin{array}{c}15.244 \\
(33.245)\end{array}$ \\
\hline controls & yes & yes \\
\hline $\begin{array}{l}\mathrm{R}^{2} \\
\mathrm{~N}\end{array}$ & $\begin{array}{l}0.48 \\
920\end{array}$ & $\begin{array}{l}0.09 \\
920\end{array}$ \\
\hline $\begin{array}{l}\text { Note. Robust standard errors are in parentheses a } \\
\text { brackets. The sample is restricted to iPhone users. } \\
\text { (Feedback (pooled) } \times \text { below or equal) is an indicator } \\
\text { in Group B (GOV:feedback) or Group D (EMP:feed } \\
\text { Week } 1 \text { was above (below or equal to) the median } \\
\text { main text for the definition of each group. partici } \\
\text { takes one for individuals who indicate in the surve } \\
\text { provide screenshots and zero otherwise. Control va } \\
\text { an indicator of a negative income shock, and the } p \\
* * * \text { indicate } p<0.10, p<0.05 \text {, and } p<0.01 \text {, respect }\end{array}$ & $\begin{array}{l}\text { omization p- } \\
(\text { pooled }) \times \\
\text { that those } \\
d \text { their outing } \\
\mathrm{r} \text { the prefect } \\
\mathrm{n} \text { indicator } \\
\mathrm{s} \text { that they } \\
\text { re outing tim } \\
\text { fixed effect }\end{array}$ & $\begin{array}{l}\text { values are in } \\
\text { above median } \\
\text { ubjects were } \\
\text { time during } \\
\text { ure. See the } \\
\text { variable that } \\
\text { are willing to } \\
\text { e in Week } 1 \text {, } \\
\text { s. **, and }\end{array}$ \\
\hline
\end{tabular}


longer for those willing to provide screenshots than those not, then we suspect experimenter demand effects. On the contrary, if we do not find any systematic difference between them, experimenter demand effects are less of a concern.

To test this hypothesis, since we lost a substantial proportion of samples by only focusing on iPhone users, we pooled our sample between the GOV and EMP conditions, thereby increasing the statistical power of the regression analyses. Table 4 shows the results. In the table, the variables of interest are the interaction terms Feedback (pooled) $\times$ above median $\times$ participate and Feedback (pooled) $\times$ below or equal $\times$ participate. As shown in the table, none of the coefficients associated with these interaction terms are statistically significant, suggesting no systematic differences in responses between those likely to show experimenter demand effects and those not. Hence, experimenter demand effects are not a major concern in the above analysis.

\subsubsection{Additional robustness checks}

We also conducted additional robustness checks on the following points. First, we examined a potential concern about priming effects and showed that our results were not contaminated by the effects (Table A.9 in the supplementary material). Next, we showed that our findings were robust by pooling the treatments to one dimension (Table A.10 in the supplementary material). Finally, we also checked the potential non-monotonic effects of baseline outing time by creating quartile dummies. We found that no substantial unexpected effects emerged, such as that the effect was only from the Q4 group (Table A.11 in the supplementary material). 


\section{Conclusion}

We conducted an online survey experiment with about 3,000 respondents in Japan to examine if and how individuals' cooperation with social distancing measures during the COVID-19 pandemic could have been improved. We focused on the power of information that allows the recipients of that information to compare their behaviors with the social norms as well as the identity of the messenger, factors known to have the potential to affect human behaviors. We found that informing individuals that their outing time was longer than others' did work to reduce outing time. In addition, informing individuals that their outing time was shorter than others' did not cause a back-firing effect if it was delivered by the typical messenger.

Our findings have important policy implications for targeting and framing policy messages. Policymakers ought to know if they should target only a subset of individuals (e.g., those with an above-median outing time) or everybody equally to maximize social welfare. If the policy message is delivered to individuals in the wrong way, it may cause unintended back-firing effects; in other words, those whose outing time was below the median value would increase their outing time after receiving such information. If that is the case, total outing time in society might not decrease and could even increase in some cases. Overall, despite being a one-shot experiment, our results suggest it is not a concern as long as the messenger is a typical one. Hence, a feasible policy intervention to induce citizens to cooperate with social distancing measures would be simply informing the whole society about society's statistics and letting them make comparisons with the social norms.

For future research, it would be important to investigate whether the repeated use of information of this kind can lead to desirable outcomes as predicted by the results of this study. Moreover, the validity of our outcome variables should be tested further, possibly 
with the help of information technology. Finally, while our information strategy using social comparisons can be generalized outside Japan, the external validity of our empirical results should be tested.

\section{References}

Ajzenman, N., T. Cavalcanti, and D. Da Mata (2020). More Than Words: Leaders' Speech and Risky Behavior during a Pandemic. SSRN Working Paper.

Allcott, H. (2011). Social norms and energy conservation. Journal of Public Economics 95(910), 1082-1095.

Banerjee, A., M. Alsan, E. Breza, A. Chandrasekhar, A. Chowdhury, E. Duflo, P. GoldsmithPinkham, and B. Olken (2020a). Messages on COVID-19 Prevention in India Increased Symptoms Reporting and Adherence to Preventive Behaviors Among 25 Million Recipients with Similar Effects on Non-recipient Members of Their Communities. NBER Working Paper.

Banerjee, A., E. Duflo, A. Finkelstein, L. Katz, B. Olken, and A. Sautmann (2020b). In Praise of Moderation: Suggestions for the Scope and Use of Pre-Analysis Plans for RCTs in Economics. NBER Working Paper.

Bassi, V. and I. Rasul (2017). Persuasion: A Case Study of Papal Influences on FertilityRelated Beliefs and Behavior. American Economic Journal: Applied Economics 9(4), $250-302$. 
Bloomberg (2020). Japan Virus Emergency Counts on Citizens to Lock Themselves Down. (https://www.bloomberg.com/news/articles/2020-03-31/japan-iscounting-on-obedient-citizens-to-lock-themselves-down).

Bottan, N. L. and R. Perez-Truglia (2018). Choosing Your Pond: Location Choices and Relative Income. NBER Working Paper.

Breza, E., S. Kaur, and Y. Shamdasani (2017). The Morale Effects of Pay Inequality. The Quarterly Journal of Economics 133(2), 611-663.

Card, D., A. Mas, E. Moretti, and E. Saez (2012). Inequality at Work: The Effect of Peer Salaries on Job Satisfaction. American Economic Review 102(6), 2981-3003.

Chen, Y., F. M. Harper, J. Konstan, and S. X. Li (2010). Social Comparisons and Contributions to Online Communities: A Field Experiment on MovieLens. American Economic Review $100(4), 1358-1398$.

Cohn, A., E. Fehr, B. Herrmann, and F. Schneider (2014). SOCIAL COMPARISON AND EFFORT PROVISION: EVIDENCE FROM A FIELD EXPERIMENT. Journal of the European Economic Association 12(4), 877-898.

Costa, D. L. and M. E. Kahn (2013). ENERGY CONSERVATION "NUDGES” AND ENVIRONMENTALIST IDEOLOGY: EVIDENCE FROM A RANDOMIZED RESIDENTIAL ELECTRICITY FIELD EXPERIMENT. Journal of the European Economic Association 11(3), 680-702.

de Quidt, J., J. Haushofer, and C. Roth (2018). Measuring and Bounding Experimenter Demand. American Economic Review 108(11), 3266-3302. 
Eckel, C., P. J. Grossman, and A. Milano (2007). Is More Information Always Better? An Experimental Study of Charitable Giving and Hurricane Katrina. Southern Economic Journal $74(2), 388-411$.

Falk, A., A. Becker, T. Dohmen, B. Enke, D. Huffman, and U. Sunde (2018). Global evidence on economic preferences. The Quarterly Journal of Economics 133(4), 1645-1692.

Frey, B. S. and S. Meier (2004). Social Comparisons and Pro-social Behavior: Testing "Conditional Cooperation" in a Field Experiment. American Economic Review 94(5), 1717-1722.

Goldstein, N. J., R. B. Cialdini, and V. Griskevicius (2008). A Room with a Viewpoint: Using Social Norms to Motivate Environmental Conservation in Hotels. Journal of Consumer Research 35(3), 472-482.

Kitamura, S. and K. Yamada (2020). Social Comparisons and Cooperation during COVID19. PsyArXiv.

Kuziemko, I., M. I. Norton, E. Saez, and S. Stantcheva (2015). How Elastic Are Preferences for Redistribution? Evidence from Randomized Survey Experiments. American Economic Review 105(4), 1478-1508.

Perez-Truglia, R. and G. Cruces (2017). Partisan Interactions: Evidence from a Field Experiment in the United States. Journal of Political Economy 125(4), 1208-1243.

Sutter, M., S. Angerer, D. Glätzle-Rützler, and P. Lergetporer (2018). Language group differences in time preferences: Evidence from primary school children in a bilingual city. European Economic Review 106(C), 21-34. 
Young, A. (2019). Channeling Fisher: Randomization Tests and the Statistical Insignificance of Seemingly Significant Experimental Results. The Quarterly Journal of Economics 134(2), 557-598.

Zizzo, D. J. (2010). Experimenter demand effects in economic experiments. Experimental Economics 13(1), 75-98. 